\title{
STUDI LITERATUR: PENGARUH TERAPI PIJAT REFLEKSI KAKI TERHADAP KELELAHAN PADA PASIEN HEMODIALISIS
}

\author{
${ }^{1}$ Latif Fajar Pamungkas, ${ }^{2}$ Fauziah H Wada, ${ }^{3}$ Puji Astuti, ${ }^{4}$ Ashar Prima \\ ${ }^{I}$ Mahasiswa Program Studi D-3Keperawatan, Jurusan Keperawatan, STIKes Bani Saleh \\ ${ }^{2}$ Departemen Maternitas, Jurusan Keperawatan, STIKes Bani Saleh \\ ${ }^{3,4}$ Departemen Keperawatan Medikal Bedah, Jurusan Keperawatan, STIKes Bani Saleh \\ Email: ${ }^{1}$ Latiffajar23@gmail.com, ${ }^{2}$ fauziah@stikesbanisaleh.ac.id, ${ }^{3}$ pujiastuti@stikesbanisaleh.ac.id, \\ "Corresponding Author: ${ }^{4}$ Ashar@stikesbanisaleh.ac.id
}

\begin{abstract}
ABSTRAK
Hemodialisis dapat menyebabkan berbagai macam masalah diantaranya kelelahan, sekitar 7-92\% pasien hemodialisis mengalami kelelahan. Salah satu terapi yang dapat mengataasi kelelahan tersebut yaitu terapi pijat refleksi kaki. Telaah literatur ini bertujuan untuk mengetahui pengaruh pijat refleksi kaki pada pasien hemodialisis dengan masalah kelelahan. Desain dalam karya tulis ilmiah ini adalah literatur review pencarian menggunakan electronic data base yaitu ProQuest dan pubmed. Kata kunci yang digunakan dalam pencarian adalah Hemodialysis, foot reflexology, fatigue. Kriteria inklusi yang digunakan pada artikel yaitu dapat diakses full text, tersedia berbahasa inggris, tahun artikel yang digunakan dibatasi sepuluh tahun terakhir (2011-2020). Hasil ditemukan masing-masing 2 artikel dari google ProQuest dan pubmed, dari ke empat artikel membahas keefektifan dari pijat refleksi kaki terhadap penurunan kelahan pada pasien hemodialisis. Hasil penelitian tersebut menunjukan manfaat pijat refleksi kaki dalam menurunkan kelelahan pada pasien hemodialisis.
\end{abstract}

Keywords: Hemodialisis, Pijat Refleksi Kaki, Kelelahan, Tinjauan Pustaka.

\section{ABSTRACT}

Hemodialysis can cause various kinds of problems including fatigue, around 7-92\% of hemodialysis patients experience fatigue. One of the therapies that can overcome this fatigue is reflexology foot massage therapy. This literature review aims to determine the effect of foot reflexology massage on hemodialysis patients with fatigue problems. The design in this scientific paper is a literature review search using electronic data base namely ProQuest and Pubmed. The keywords used in the search are hemodialysis, foot reflexology, fatigue. inclusion criteria used in the article are accessible full text available in english and indonesian years the articles used are limited to the last ten years, results are found each of 2 articles from google schoolar and pubmed, from the four articles discussing the effectiveness of foot reflexology massage on the decline fatigue in hemodialysis patients. The results of the study showed the benefits of foot reflexology in reducing fatigue in hemodialysis patients.

Keywords: Hemodialysis, Foot Reflexology, Fatigue, Literature Review.

\section{PENDAHULUAN}

Gagal Ginjal Kronik (GGK) merupakan penyakit yang sangat berbahaya karena penyakit ini dapat berlangsung lama dan mematikan. Gagal ginjal kronik menjadi masalah kesehatan dunia karena sulit disembuhkan, dengan peningkatan angka kejadian, prevalensi dan tingkat morbiditasnya (Ali et al., 2017). Badan Kesehatan Dunia (WHO) menyatakan pertumbuhan jumlah penderita gagal ginjal pada tahun 2013 telah meningkat 50\% dari tahun sebelumnya. Pravalensi dan kejadian gagal ginjal di Amerika Serikat terus meningkat $50 \%$ di tahun 2014, data menunjukkan bahwa setiap tahun 200.000 orang Amerika menjalani hemodialisis karena gangguan ginjal kronis artinya 1140 dalam satu juta orang Amerika adalah pasien dialisis (Widyastuti et al., 2014).

Hasil Riset Kesehatan Dasar (Riskesdas) tahun 2018, menjelaskan prevalensi gagal ginjal kronik yang terdiagnosis oleh dokter sebesar 3,8\% di Indonesia. Didapatkan prevalensi gagal ginjal terminal yang terdiagnosis dokter tertinggi terdapat di provinsi Kalimantan Utara 6,4\%. Prevalensi gagal ginjal terminal yang terendah terdapat di provinsi Sulawesi Barat sebesar 1,8\%, di provinsi Jawa Barat jumlah penderita gagal 
ginjal terminal sebanyak 4\%. (Riskesdas, 2018).

Dampak yang disebabkan dari hemodialisi yaitu berkaitan dengan kualitas hidup, penurunan kondisi fisik seperti kelelahan, penyakit kardiovaskular (CVD) dan kematian, ini bisa sangat melemahkan dan mengganggu baik secara emosional maupun fisik (Chiaranai, 2016). Pasien akan mengalami keterbatasan dalam kebebasan, kehilangan percaya diri dan kehilangan koneksi sosial (Monaro et al., 2014). Kelelahan menjadi hal yang sangat penting dilaporkan berdasarkan penulisan klinis pada pasien HD (Evangelidis et al., 2017).

Intervensi untuk mengurangi kelelahan dapat dilakukan dengan terapi famakologis ataupun non farmakologis. Terapi nonfamakologis yang diberikan seperti terapi nutrisi, yoga, akupresur dan terapi pijat refleksi kaki. Terapi pijat melibatkan palpasi jaringan lunak dan otot, pijatan adalah sentuhan terapi yang mengarah untuk relaksasi fisik dan mental dan mampu menghasilkan transmisi energi antara praktisi dan subjek, dan oleh karena itu dapat digunakan untuk membantu pasien mengatasi kelelahan (Bicer \& Çürük, 2016).

Terapi pijat refleksi kaki banyak dilakukan karena tidak ada efek samping pada penerapannya dan dirasa aman untuk dilakukan juga tidak ada efek jangka panjang. Pijat refleksi adalah pengobatan tertua di dunia, berdasarkan teknik pijat ilmiah dan telah dikembangkan sejak zaman Cina dan Mesir kuno. Gambar-gambar ilmiah paling utama dari pijat refleksi ditemukan di makam Ankhmahor di Mesir pada 2500 SM (Shady \& Ali, 2019).

\section{METODE}

a. Formulasi PICO

Dampak yang disebabkan dari hemodialisi yaitu berkaitan dengan kualitas hidup, penurunan kondisi fisik seperti kelelahan, penyakit kardiovaskular (CVD) dan kematian sehingga diperlukan terapi komplementer untuk menangani masalah tersebut, salah satunya yaitu pijat refleksi kaki (Chiaranai, 2016). Untuk meyakinkan tenaga kesehatan untuk keefektifan terapi refleksi kaki pada pasien Hemodialisis yang mengalami kelelahan perlu dilakukan pencarian literature, formulasi pencarian literature sebagai berikut:

Population : Pasien Hemodialisis

Intervention : Pijat Refleksi Kaki

Comparison : :

Outcomes : Kelelahan

Berdasarakan formulasi PICO diatas maka penulis merumuskan research questions yaitu apakah pemberian pijat refleksi kaki pada pasien hemodialisis yang mengalami kelelahan efektif dalam menurunkan tingkat kelelahan?

b. Search Strategi

Pencarian literature dilakukan dengan mencari publikasi artikel dari literatur pendidikan kesehatan dan medis, pencarian dilakukan menggunakan database: ProQuest dan pubmed/NCBI pencarian literature menggunakan keyword Hemodialysis, Foot Reflexology, Fatigue dari hasil pencarian di database, ditemukan 406 artikel yang relevant sesuai Keyword, terdiri dari ProQuest (350) pubmed/NCBI (56).

Setelah itu dilakukan pembatasan tahun dengan rentang 10 tahun terakhir (20112020) dan didapatkan 305 artikel pada ProQuest dan 45 artikel pada pubmed, lalu membaca judul satu persatu juga melakukan pemilahan jurnal sesuai dengan kriteria inklusi (artikel yang diterbitkan dari tahun 2011-2020, berbahasa Inggris, tidak berbayar, dan Full text) hanya didapatkan kurang lebih 7 judul yang sesuai dengan keyword dari kedua data base tersebut lalu satu persatu dibaca abstraknya dan hanya tersisa 4 karena 2 artikel yang lain berbahasa arab dan turki dan 1 artikel lainnya merupakan penelitian perbandingan. 
c. Tabel deskripsi ringkasan artikel

Tabel 1. Tabel Deskripsi Ringkasan Artikel

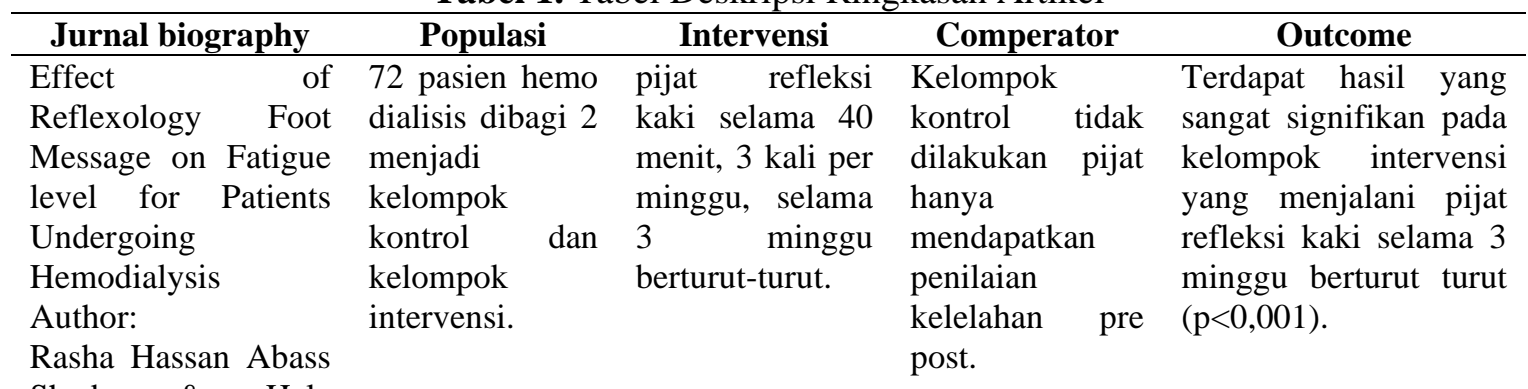

Shady \& Hala

Mohamed

Abdelhamed Ali (2019)

$\begin{array}{lr}\text { Effect of } & \text { Feet } \\ \text { Reflexology } & \text { on } \\ \text { Fatigue of End-Stage } \\ \text { Renal } \\ \text { Patients Disease } \\ \text { Hemodialysis } \\ \text { Treatment } \\ \text { Author: } \\ \text { Antonius Jumadi, } \\ \text { Fitriana Suprapti \& } \\ \text { Sudibyo Supardi } \\ \text { (2019) }\end{array}$

Effectiveness of foot reflexology on fatigue among patients with chronic renal failure admitted in nephrology ward at goverment rajaji hospital, madurai. Author:

Ms. Yamini Devi.V., M.Sc (2016)

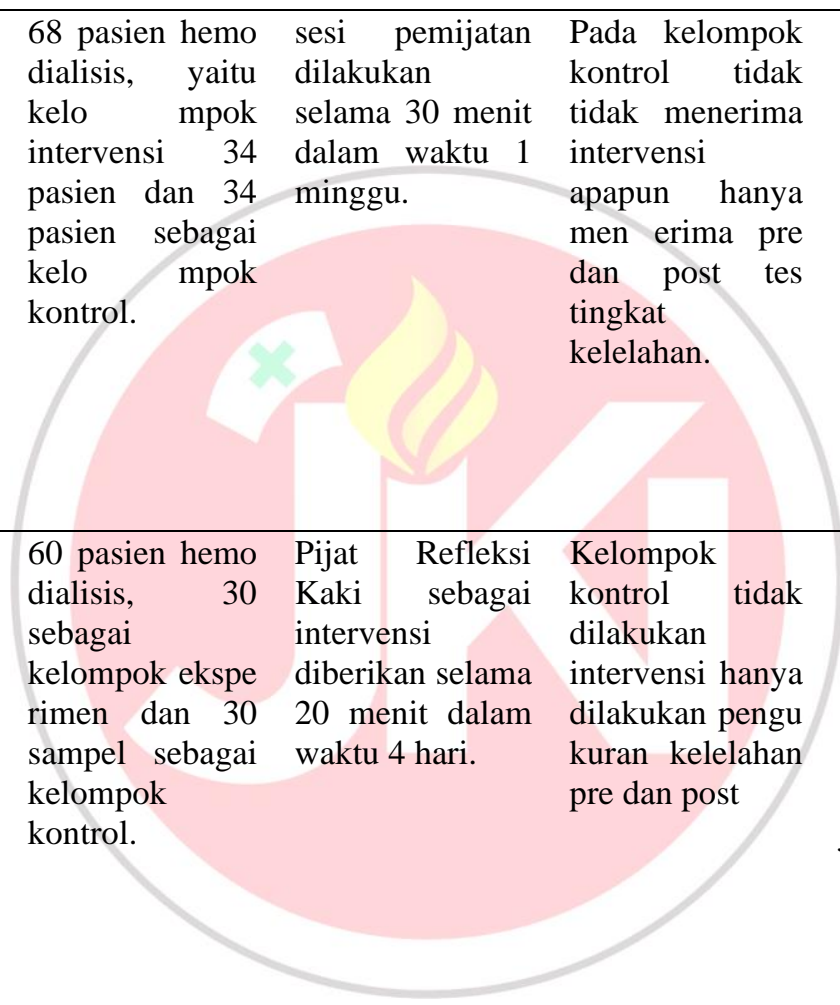

Setelah pasien dipijat selama 1 minggu pasien mnegalami penurunan kelelahan yang signifikan. Tingkat signifikansi refleksologi $\quad 0,000$ <alpha 0,05 berarti pijat refleksi kaki secara signifikan mempengaruhi penurunan tingkat kelelahan.

Dalam kelompok

eksperimen, dalam pretest, skor kelelahan pasien 7,33 yaitu kelelahan sedang dan posttest mereka memiliki skor 4,37, jadi selisihnya adalah 2,96 skor setelah refleksi kaki. Ini menunjukan bahwa pijat refleksi efektif dalam menurunkan kelelahan.

\begin{tabular}{|c|c|c|c|c|}
\hline $\begin{array}{l}\text { The effect of } \\
\text { reflexology applied } \\
\text { on haemodialysis } \\
\text { patients with fatigue, } \\
\text { pain and cramps } \\
\text { Author: } \\
\text { Gülistan Özdemir } \\
\text { RN, Nimet Ovayolu } \\
\text { RN PhD, Özlem } \\
\text { Ovayolu RN PhD }\end{array}$ & $\begin{array}{lr}80 \text { pasien } & \text { hemo } \\
\text { dialisis, } & 40 \\
\text { pasien } & \\
\text { intervensi dan } \\
40 \quad \text { pasien } \\
\text { kontrol. }\end{array}$ & $\begin{array}{l}\text { Pijat refleksi } \\
\text { diberikan selama } \\
\text { Total } 30 \text { menit, } \\
\text { setiap kaki } 15 \\
\text { menit. } \\
\text { Pemberian } \\
\text { diberikan selama } \\
1 \text { minggu. }\end{array}$ & $\begin{array}{l}\text { Kelompok } \\
\text { kontrol tidak } \\
\text { mendapatkan } \\
\text { intervensi pijat } \\
\text { refleksi kaki }\end{array}$ & $\begin{array}{lr}\text { Perbedaan } & \text { sangat } \\
\text { signifikan ditemukan } \\
\text { antara kedua kelompok } \\
\text { setelah aplikasi } \\
\text { refleksologi, dan } \\
\text { penurunan yang khas } \\
\text { terdapat pada tingkat } \\
\text { kelelahan pasien di } \\
\text { kelompok eksperimen } \\
(\mathrm{P} \quad<0,001) \text { I Itu } \\
\text { menunjukan bahwa } \\
\text { terdapat penurunan } \\
\text { kelahan } \\
\text { signifikan yang } \\
\text { kelompok eksperimen. }\end{array}$ \\
\hline
\end{tabular}




\section{HASIL DAN PEMBAHASAN}

Setelah dilakukan pencarian menggunakan kriteria inklusi dan eksklusi didapatkan 4 jurnal full text yang sesuai kriteria validitas dan relevansi yang baik.

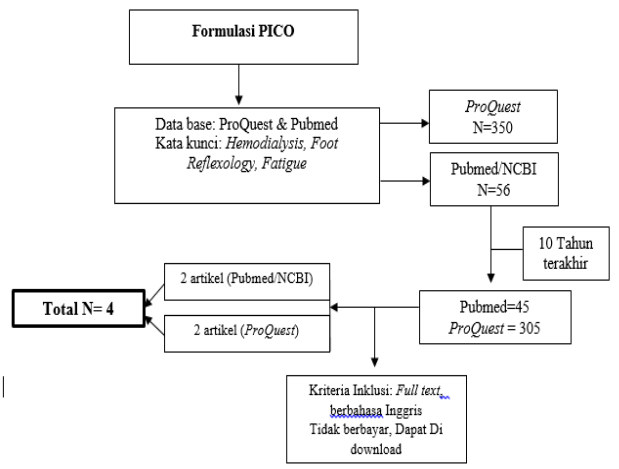

Gambar 1. Searching Strategy Flow Chart

Pembahasan hasil telaah evidance base berdasarkan teori dan hasil penelitian didapatkan hasil sebagai berikut:

a. Karakteristik Responden

Dalam penelitian yang dilakukan oleh Shady \& Ali pada tahun 2019 penelitian dilakukan pada jenis kelamin perempuan dan laki laki dengan jumlah 46 laki-laki dan 26 perempuan dikedua kelompok, Usia dari 20 hingga 60 tahun, mampu berkomunikasi secara verbal, bebas dari salah satu masalah berikut: Neuropati perifer, cedera pada kaki termasuk memar parah, ulserasi, luka terbuka, atau luka baru-baru ini) luka bakar, penyakit pembuluh darah perifer di tungkai bawah, penyakit kulit termasuk psoriasis akut atau eksim (Shady \& Ali, 2019).

Sementara pada penelitian yang lain yang dilakukan oleh Jumadi et al, pada tahun 2019 dilakukan pada 31 responden dewasa menengah dan dewasa awal, Sebagian besar jenis kelamin dari kelompok kontrol perempuan dan kelompok intervensi sebagian besar pria, Mayoritas pendidikan responden adalah sekolah menengah pada kelompok kontrol, sedangkan sekolah dasar pada kelompok intervensi. Dengan kriteria inklusi responden adalah pasien dengan ESRD, kesadaran penuh, menjalani perawatan hemodialisis, keluhan kelelahan dan bersedia responden penelitian dan tekanan darah $<200 / 120 \mathrm{mmHg}$ dan kadar glukosa 70-300 $\mathrm{mg} / \mathrm{dl}$ (Jumadi et al., 2019).

Sedangkan penelitian lain yang dilakukan oleh Yamini, pada tahun 2016 melakukan penelitian pada responden dengan usia kelompok eksperimen sekitar 21-65 tahun kriteria inklusi adalah Pasien dengan gagal ginjal kronis dirawat di bangsal nefrologi di Pemerintah Rumah Sakit Rajaji, Madurai. Pasien yang bersedia berpartisipasi, pasien mengerti bahasa Tamil atau bahasa Inggris, pasien yang memiliki skor kelelahan 3 dan lebih tinggi sesuai dengan persediaan tingkat kelelahan, kriteria pengecualian: pasien yang sakit kritis, pasien yang menderita ulkus kaki, pasien yang kehilangan sensasi perifer (Devi, 2016).

Sedangkan karakteristik responden pada penelitian yang dilakukan oleh Odzemir et al, pada tahun 2013 melakukan peneliatan kepada responden dengan usia 18 - 63 tahun, di kelompok eksperimen terdapat 27 perempuan dari 40, kriteria inklusi yaitu memiliki kesadaran dan orientasi penuh, tidak memiliki masalah komunikasi, menerima hemodialisis tiga kali seminggu, telah menerima hemodialisis selama setidaknya 6 bulan Pasien tidak dengan luka kaki terbuka, fraktur yang mencurigakan, terbakar, trombosis vena dalam dan neuropati perifer dikeluarkan dari penelitian (Ozdemir et al., 2013).

b. Intervensi dan instrumen

Berbagai macam intervensi yang dilakukan untuk melakukan terapi refleksi kaki, pada penelitian yang dilakukan oleh Shady \& Ali intervensi dilakukan pada kelompok koontrol dan kelompok study Intervensi Keperawatan yang diberikan adalah pasien diberikan pijat refleksi selama 40 menit setelah sesi hemodialisis pada semua titik refleks pada kedua kaki, 3 kali per minggu, selama 3 minggu berturut-turut dengan total 9 sesi pijat. Instrumen untuk mengukur kelelahan pada penelitian ini menggunakan instrumen VAS-F (Visual Analog Scale Fatigue) dan MAF (Multidimensional Assessment of Fatigue Scale) (Shady \& Ali, 2019).

Sementara pada penelitian yang lain yang dilakukan oleh Jumadi et al, intervensi dilakukan pada kelompok intervensi setelah 10 menit pasien menjalani hemodialisis, yaitu peneliti melakukan refleksi kaki sesuai dengan prosedur yang dibuat sebelumnya. perawatan refleksologi kaki dilakukan tiga kali seminggu dan pengukuran tingkat 
kelelahan dilakukan satu kali setelah perawatan refleksi kaki ketiga (post test). Instrumen untuk mengukur kelelahan pada penelitian ini menggunakan instrumen MAF (Multidimensional Assessment of Fatigue Scale) (Jumadi et al., 2019).

Selanjutnya intervensi yang dilakukan oleh Yamini Devi diberikan untuk kelompok eksperimen. Eksperimental kelompok menerima refleksi kaki selama 4 hari berturut-turut. Pijat Refleksi Kaki sebagai intervensi diberikan selama 20 menit pada kedua kaki secara terpisah (masing-masing kaki 10 menit). Instrumen untuk mengukur kelelahan pada penelitian ini menggunakan instrumen BIF (Brief Fatigue Inventory) (Devi, 2016).

Pada intervensi yang dilakukan oleh Odzemir et al, Pijat refleksi diterapkan untuk Total 30 menit, 15 menit untuk setiap kaki. Lima menit dari 15 menit sesi refleksologi tidak digunakan untuk teknik relaksasi yang diberikan pada awal sesi, teknik relaksasi diberikan pada akhir sesi selama 3 menit. Instrumen untuk mengukur kelelahan pada penelitian ini menggunakan instrumen Piper Fatigue Scale (Ozdemir et al., 2013).

c. Efektivitas

Dalam penelitian yang dilakukan oleh Shady \& Ali terbukti signifikan dengan kelelahan yg dialami kelompok studi dari kelelahan berat hingga menjadi kelelahan ringan setelah sesi pemijatan ke 9 dengan $p$ value $(\mathrm{p}=0,0001)$. Pijat kaki juga memiliki manfaat psikologis termasuk relaksasi dan peningkatan rasa kesejahteraan dengan merangsang pelepasan endorfin yang bertindak sebagai penghilang rasa sakit alami dan elevator mood (Shady \& Ali, 2019). Ini sejalan dengan Diroll 2017 yang menunjukkan bahwa penerapan pijat refleksi kaki dapat merangsang jalur saraf untuk melepaskan kemacetan dan mempromosikan respons relaksasi untuk seluruh tubuh (Diroll, 2017).

Sementara itu uji statistik yang dilakukan oleh Jumadi et al, menunjukkan perbedaan tingkat kelelahan sebelum dan sesudah kaki pijat refleksi $(p=0,000)$ dengan penurunan tingkat kelelahan dari 26 menjadi 22 yang artinya terdapat hasil yang signifikan dalam penurunan kelelahan setelah dilakukan pijat refleksi kaki (Jumadi et al., 2019).
Sejalan dengan wang et al yang mengatakan bahwa pijat refleksi memfasilitasi sirkulasi darah ke seluruh tubuh dan merangsang produksi endorfin yang berfungsi untuk bersantai tubuh dan dapat memberikan kesegaran dan kenyamanan tubuh (Wang et al., 2008).

Dalam penelitian yang lain yang dilakukan oleh Yamini, kelompok eksperimen dalam pretest pasien mengalami 7,33 skor kelelahan dan posttest mereka memiliki skor 4,37, jadi selisihnya adalah 2,96 skor setelah refleksi kaki. Perbedaan ini besar dan signifikan setelah dilakukan pijat refleksi kaki $(\mathrm{p}=0,0001)$. Ahli refleksiologi mendalilkan bahwa kerusakan fungsi organ atau sistem tubuh mengarah ke deposit asam urat atau garam kristal kalsium. Pada gilirannya, akan menimpa pada ujung saraf di kaki dan menghalangi aliran getah bening. Memijat area ini akan memecah hambatan tersebut dan menurunkan deposit kristal sehingga dapat diserap kembali dan dihilangkan (Devi, 2016).

Sementara dalam penelitian yg dilakukan oleh Odzemir et al, pada kelompok eksperimen terdapat penurunan kelelahan yang signifikan setelah dilakukan pre post test kelelahan setelah dilakukan pijat refleksi kaki ( $\mathrm{p}<0,0001)$. (Özdemir et al., 2013) Sesuai dengan yang dikatakan oleh Wilkinson et al yaitu dengan bantuan refleksologi, aliran energi dalam tubuh ini dapat membantu pasien dalam memulihkan lebih banyak energi dengan mempercepat sirkulasi darah dan karenanya memungkinkan oksigen dan nutrisi mudah ditransfer ke jaringan. (Wilkinson et al, 2008).

\section{KESIMPULAN}

Berdasarkan hasil Studi Literature menerangkan bahwa dari 4 artikel menunjukan pijat refleksi kaki efektif dalam menurunkan tingkat kelelahan pada pasien hemodialisis.

\section{REFERENCES}

Ali, A. R. B., Masi, G. N. M., \& Kallo, V. (2017). Perbandingan Kualitas Hidup Pasien Gagal Ginjal Kronik Dengan Comorbid Faktor Diabetes Melitus Dan Hipertensi. E-Jurnal Keperawatan, 5(1), 43.https://doi.org/10.1017/CBO9781107 415324.004 . 
Bicer, S., \& Çürük, G. N. (2016). Examination of the Nursing Theses on Practices of Complementary and Supportive Medicine for Individuals Undergoing Hemodialysis in Turkey: A Literature Review. World Journal of Preventive Medicine, 4(2), 40-46. https://doi.org/10.12691/jpm-4-2-3.

Chiaranai, C. (2016). The Lived Experience of Patients Receiving Hemodialysis Treatment for End-Stage Renal Disease: A Qualitative Study. Journal of Nursing Research, 24(2), 101-108. https://doi.org/10.1097/jnr.00000000000 00100.

Devi, Y. (2016). Effectiveness of Foot Reflexology on Fatigue Among Patients With Chronic Renal Failure Admitted in Nephrology Ward At Government Rajaji Hospital , Madurai . Master of Science in Nursing Effectiveness of Foot Reflexology on Fatigue Among Patients With Chro.

Evangelidis, N., Tong, A., Manns, B., Hemmelgarn, B., Wheeler, D. C., Tugwell, P., Crowe, S., Harris, T., Van Biesen, W., Winkelmayer, W. C., Sautenet, B., O'Donoghue, D., TamTham, H., Youssouf, S., Mandayam, S., Ju, A., Hawley, C., Pollock, C., Harris, D. C., .. Craig, J. C. (2017). Developing a Set of Core Outcomes for Trials in Hemodialysis: An International Delphi Survey. American Journal of Kidney Diseases, 70(4), 464-475. https://doi.org/10.1053/j.ajkd.2016.11.02 9.

Jumadi, A., Suprapti, F., \& Supardi, S. (2019). Effect of Feet Reflexology on Fatigue of End-Stage Renal Disease Patients with Hemodialysis Treatment.
International Journal of Health, Nursing \& Medicine, 3(2), 90-99.

Monaro, S., Stewart, G., \& Gullick, J. (2014). A "lost life": Coming to terms with haemodialysis. Journal of Clinical Nursing, 23(21-22), 3262-3273. https://doi.org/10.1111/jocn.12577.

Özdemir, G., Ovayolu, N., \& Ovayolu, Ö. (2013). The effect of reflexology applied on haemodialysis patients with fatigue, pain and cramps. International Journal of Nursing Practice, 19(3), 265-273. https://doi.org/10.1111/ijn.12066.

Riskesdas, K. (2018). Hasil Utama Riset Kesehata Dasar (RISKESDAS). Journal of Physics A: Mathematical and Theoretical, 44(8), 1-200. https://doi.org/10.1088/17518113/44/8/085201.

Shady, R. H. A., \& Ali, H. M. A. (2019). Effect of Reflexology Foot Message on Fatigue level for Patients Undergoing Hemodialysis. International Journal of Nursing, $\quad 6(1), \quad 151-170$. https://doi.org/10.15640/ijn.v6n1a17.

Wang, M., Tsai, P., Lee, P., Chang, W., Yang, C., \& Edd, P. L. (2008). The efficacy of reflexology: systematic review. January, 512-520. https://doi.org/10.1111/j.13652648.2008.04606.x.

Widyastuti, R., WR.Butar-Butar, \& Bebasari, E. (2014). Korelasi Lama Menjalani Hemodialisis Dengan Indeks Massa Tubuh Pasien Gagal Ginjal Kronik. 1(2), 1-12.

Wilkinson, S., Lockhart, K., Gambles, M., \& Storey, L. (2008). Reflexology for Symptom Relief In Patirnts With Cancer. Cancer Nursing, 31(5), 354-360. 